\title{
Del individuo o de la producción aleatoria. Notas de investigación sobre el pensamiento de Louis Althusser
}

\author{
José Francisco Barrón Tovar
}

\section{Modo de uso}

Cuidémonos de jugar con las palabras.

¿Por qué la filosofía pelea por palabras? [...] en la lucha política, ideológica y filosófica las palabras son también armas: explosivos, calmantes o venenos. Toda la lucha de clases puede, a veces, resumirse en la lucha por una palabra, contra otra palabra. Ciertas palabras luchan entre ellas como enemigos. Otras dan lugar a equívocos, a una batalla decisiva pero indecisa. [...] contra las palabras-mentira, contra las palabras-equívocos; por las palabras justas. Combate por "matices".

Louis Althusser

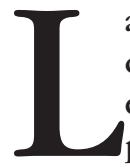

a escisión es la máquina especulativa althusseriana. Trabaja a la vez como máquina de distinción y elaboración de conceptos y como estilo expositivo. ${ }^{1}$ Dos mecanismos principales la ponen en operación. El primero se ejerce en el estilo expositivo a la manera de un viejo tropo retórico. Althusser utiliza adrede este tropo retórico y postula la posibilidad de decir lo nuevo a partir de un código ya convencional -una euresis que se adecua a lo prepón. Así, argumentará de manera reiterativa que para poder expresar sus revoluciones teóricas tanto Freud como Marx tuvieron "que pen-

${ }^{1}$ Louis Althusser, "De El capital a la filosofía de Marx", en L. Althusser y Étienne Balibar, Para leer El capital. Trad. de Marta Harnecker. México, Siglo XxI, 1974, p. 20. Se afirma la pregunta "¿qué es leer?" como la cuestión que constituye "nuestro tiempo". 
sar su descubrimiento y su práctica con conceptos importados", ${ }^{2}$ viejos. El segundo mecanismo se ejerce en la distinción conceptual palabra/concepto. Althusser afirma que son diferentes: "La palabra [...] es sólo una palabra. El lugar que ocupa y la función que ejerce [en un sistema de pensamiento o de prácticas] le confieren su sentido". ${ }^{3}$ La palabra tiene una función provisional para describir, "sin pensar", lo que ocurre. En cambio, el concepto "explica", "piensa". El concepto debe confundirse con el aparato especulativo que distribuye y hace aceptable tales y cuales palabras. El concepto es una máquina de producir discurso nuevo.

La cuestión se complica cuando Althusser utiliza esta distinción palabra/ concepto, a la vez que el tropo de decir lo nuevo con lo viejo al producir su pensamiento. Así, en su escritura habría que distinguir, por un lado, las palabras de los conceptos y el discurso que dice lo viejo del que dice lo nuevo, pero también, y por otro lado, habría que distinguir los conceptos y las palabras viejos de las palabras y los conceptos nuevos. Se producen así problemas políticos de lectura, de distinción de palabras, de diferenciación conceptual al interior de sus textos: ¿cómo saber cuándo se lee revolucionariamente y cuándo sólo se reproduce un código político?, ¿en qué momento se está produciendo una lectura y en qué momento sólo se mantiene una ya solidificada y reaccionaria?, y ¿existe un saber, una ciencia, que pueda distinguir entre lecturas? Una manera para distinguirlas sería postular que el mecanismo especulativo de diferenciación palabra/concepto gobierna el mecanismo estilístico de lo nuevo dicho en palabras viejas.

El uso de estas estrategias especulativo-escriturísticas permite a Althusser producir conceptos nuevos al interior de las convenciones políticas y filosóficas, y aducir que en esta novedad conceptual se halla lo verdadero. De allí la insistencia althusseriana de "concebir el conocimiento como producción": “' "lo verdadero' 'se inicia a sí mismo' como producto, en la doble acepción del término 'producto' (resultado del trabajo de un proceso que le descubre), como probándose en su producción misma”. 5 De allí que

Althusser añade: "a partir de Marx deberíamos comenzar a sospechar lo que quiere decir leer y, por tanto, escribir" (ibid., p. 21). Althusser sostendrá que toda su labor filosófico-política se trata de una transformación en el ejercicio y en el concepto de la práctica de la lectura y escritura.

${ }^{2}$ L. Althusser, "Freud y Lacan", en Escritos sobre psicoanálisis. Freud y Lacan. Trad. de Eliane Cazenave-Tapie. México, Siglo XxI, 1996, p. 29, n. 7.

${ }^{3}$ L. Althusser, "Respuesta a John Lewis", en Para una crítica de la práctica teórica. Trad. de Santiago Funes. Madrid, Siglo XXI, 1974, p. 37, n. 15.

${ }^{4}$ L. Althusser, "De El capital a la filosofía de Marx", en op. cit., p. 40.

${ }^{5}$ L. Althusser, Elementos de autocrítica. Trad. de Miguel Barroso. Barcelona, Laia, 1975, p. 51. 
Althusser al atreverse a afirmar una supuesta filosofía marxista hable de "un agua viva que todavía no ha corrido". ${ }^{6}$ Esta "agua viva" "corre bajo" palabras y conceptos que inducen a confusión. Así, las distinciones estilístico-conceptuales se multiplicarán de acuerdo a un aparato esquizofrénico productor, y éste pasará desapercibido bajo y en las mismas palabras que lo afirman. Pero, asegura Althusser, "vendrá el día en que se intente y acepte llamar a las cosas por su nombre y por ello investigar con cuidado, [...] incluso si es necesario precisarlo según se avanza, el nombre, quiero decir el concepto" ${ }^{7}$ que merecen las cosas. Día de una lectura en la que se ejerza "el encuentro entre los conceptos y las cosas". ${ }^{8}$

\section{Vendrá un día}

Y si se va a escribir sobre Althusser hay que someterse a lo que llama el primado de la función práctica sobre la función teorética, y concebir el conocimiento como producción. Este sometimiento nos llevaría a producir aquí una lectura metafórica que repensaría la problemática relación prácticas de lo político/cuerpo individual. Este sometimiento debe llevarse a cabo en conformidad con las "dos teorías generales" que Althusser afirmaba dominaban la labor conceptual del día de hoy: 1) el materialismo aleatorio ${ }^{9}-0$ puesta en funcionamiento de una labor especulativa que intenta "pensar lo nuevo en ausencia de todas las condiciones",$-{ }^{10}$ y 2) "teoría general del significante, que estudia

${ }^{6}$ L. Althusser, "De El capital a la filosofía de Marx", en op. cit., p. 36.

${ }^{7}$ L. Althusser, "Nota. Sobre la crítica del culto a la personalidad", en Para una crítica de la práctica teórica, p. 86.

${ }^{8}$ L. Althusser, Para un materialismo aleatorio. Trad. de Pedro Fernández Liria, Luis Alegre Zahonero y Guadalupe González Diéguez. Madrid, Arena Libros, 2002, p. 62.

${ }^{9}$ Se acepta aquí que el pensamiento althusseriano alcanza su expresión conveniente en el materialismo aleatorio. Lo que llamaba materialismo dialéctico e histórico sólo son "notas de investigación" para encontrar una expresión conveniente. Sobre la concepción althusseriana de las "notas de investigación", $c f$. carta del 14 de octubre de 1966 a Étienne, allí escribe: "debe entenderse que son notas de investigación, por lo tanto, ensayos, tentativas de enfoque, reflexiones que implican riesgos teóricos de error, y que están sujetos a rectificación y crítica. Por ello no hay que temer ni un instante iniciar ensayos que puedan ser errores, hipótesis que puedan ser aventuradas, y que deberían ser tachadas o enderezadas" (L. Althusser, Escritos sobre psicoanálisis. Freud y Lacan, p. 100).

${ }^{10}$ L. Althusser, "La solitude de Machiavel", en Future Antérieur, núm. 1, pp. 26-49, apud Antonio Negri, "Maquiavelo y Althusser", en L. Althusser, Maquiavelo y nosotros. Trad. de Beñat Baltza Álvarez. Madrid, Akal, 2004, p. 14. 
los mecanismos y los posibles efectos de todo discurso" 11 - o el análisis de toda "empresa de convicción-persuasión" ejercida por el lenguaje.

La imbricación de estas dos teorías es lo que Althusser llama "revolución teórica" -registrada tanto en Marx como en Freud. ${ }^{12}$ Esta operación revolucionaria en el ejercicio del pensamiento debe ponerse en funcionamiento en cada coyuntura (política, económica, social, discursiva, etcétera) singular y aleatoria a la vez como ejercicio constante de lectura de metáforas y como producción continua de efectos sobre cuerpos singulares; es decir, sólo se producen prácticas políticas si se producen efectos retóricos coyunturales sobre las prácticas de los cuerpos de los individuos. Así, toda la labor althusseriana debería dirigirse - con su caterva de conceptos: distinción ideología/ ciencia, sobredeterminación, determinación por las relaciones, subversión, desplazamiento, última instancia, eficiencia de la causa ausente, etcéterahacia este ejercicio retórico-materialista.

Para ejemplificar este ejercicio se analizarán los dispositivos conceptuales "ideología", "aparatos ideológicos de Estado" (AIE) e "interpelación ideológica" (II). Ya que esta empresa se ejerce sobremanera en estos mecanismos y sus operaciones. Pero al final, toda esta labor debe retraducirse en "última instancia" en una reinterpretación del concepto del cuerpo material singular (individuo) como espacio de operación política y de resistencia. Cuerpo singular diferente al sujeto de prácticas sociales, cuerpo como instancia aleatoria de resistencia y ámbito de lo político. Y es que la empresa detrás del echar a andar el mecanismo de la "interpelación ideológica" es poner en funcionamiento múltiples aparatos de producción aleatoria de subjetividades políticas.

La imbricación mecanismos del lenguaje retórico/operaciones aleatorias del cuerpo singular es lo que aquí se nominará el pensamiento de Althusser. Pensamiento que se retraduce, en última instancia, en prácticas singulares de lo político.

${ }^{11}$ Carta enviada a Franca el 13 de septiembre, en L. Althusser, "Tres notas sobre la teoría de los discursos", en Escritos sobre psicoanálisis. Freud y Lacan, p. 102.

${ }^{12}$ Lo que Althusser llama "revolución teórica" de Marx y Freud debe entenderse como el trastorno de las formas de pensamiento tradicionales y la introducción de formas de pensamiento revolucionarias. Revolución en el sentido de una modificación de los problemas, de la relación entre las prácticas y su objeto. 


\section{Afirmar un materialismo retorcido}

No basta con deletrear las palabras de una teoría, hay que ver cómo actúa.

Louis Althusser

Hay que dejar muy claro el problema que Althusser elabora en los dispositivos conceptuales ideología, aparatos ideológicos de Estado e interpelación ideológica: con tales dispositivos, Althusser abre, en términos políticos, la discusión sobre los aparatos (políticos, sociales, discursivos, económicos, institucionales, etcétera) de producción de individualidades. El texto "Ideología y aparatos ideológicos de Estado" afirma que la II es un mecanismo práctico reapropiado e implementado por el "aparato de Estado" para producir trabajadores que puedan y quieran ser explotados en las circunstancias de las instituciones producidas por las relaciones de producción capitalistas.

La puesta en funcionamiento de los dispositivos conceptuales ideología, AIE e II tiene un "sentido completamente positivo". ${ }^{13}$ Antes de tener un funcionamiento de ataque contra cualquier dispositivo práctico-conceptual que comience a pensar a partir de la evidencia de "la imagen burguesa de 'el hombre", Althusser echa a funcionar tales dispositivos para "desplazar la pregunta" y "desembarazarse del fetichismo de 'el hombre". ${ }^{14}$ Su cometido último con tal constelación conceptual es elaborar "la teoría del mecanismo de producción del efecto de sociedad en el modo de producción capitalista". ${ }^{15}$ Althusser afirmará con vigor que el efecto-sociedad en el capitalismo del día de hoy requiere un "efecto-sujeto" 16 para ejercerse, y que el funcionamiento de las relaciones de producción de la sociedad capitalista actual se ejerce como un aparato de producción de "efectos de subjetividad". ${ }^{17}$

Determinadas preguntas devienen índices de desplazamiento especulativo: ¿cómo se logra que los individuos hagan y continúen con la realización, deseen

${ }^{13}$ L. Althusser, "Ideología y aparatos ideológicos de Estado", en La filosofía como arma de la revolución. Trad. de Óscar del Barco, Enrique Román y Óscar Molina. México, Siglo XXI, 1974, p. 122. Balibar encuentra en este dispositivo un "aspecto ambivalente, al mismo tiempo 'constructivo' y 'deconstructivo'” (É. Balibar, "El no-contemporáneo", en Escritos por Althusser. Trad. de Heber Cardoso. Buenos Aires, Nueva Visión, 2004, p. 85). Balibar trata de resaltar a la vez la tarea crítica de la noción de ideología que se ejerce sobre la figura del "hombre" y la "producción de individualidades" necesarias para la transformación de las relaciones sociales.

${ }^{14}$ L. Althusser, "Respuesta a John Lewis", en op. cit., p. 36.

${ }^{15}$ L. Althusser, "De El capital a la filosofía de Marx", en op. cit., p. 73.

${ }^{16}$ L. Althusser, "Tres notas sobre la teoría de los discursos", en op. cit., p. 116.

${ }^{17}$ Ibid., p. 115. 
la realización de ciertas prácticas, quieran seguir moviendo sus cuerpos de ciertas maneras determinadas que salvaguardan la organización de una sociedad capitalista?; ¿cómo se consigue que un obrero no deje de querer actuar como un agente de las relaciones sociales de producción capitalistas a la mañana siguiente después de irse a la cama, o después de una gran tristeza o borrachera?; ¿cómo ciertas prácticas individuales devienen instituciones capitalistas?; ¿cómo se logra que prácticas anteriormente contingentes se solidifiquen de acuerdo con relaciones capitalistas?; ¿cómo se hace un uso político -de explotación- de determinadas prácticas contingentes?, y ¿cómo se capitalizan las prácticas y las pasiones de los individuos?

Las preguntas cuestionan sobre algo cotidiano, algo imperceptible: sobre las prácticas y deseos de los individuos para continuar determinadas prácticas cotidianas. El gobierno actual para ejercerse, afirmará Althusser, requiere a los individuos, sus prácticas y sus pasiones. Requiere que tales individuos repitan sus modos de vivir para poder repetir las relaciones de producción. El problema es la "reproducción de las fuerzas productivas" ${ }^{18}$ re-producción de cierto tipo de prácticas que pueden capitalizarse fácilmente, que los individuos deseen hacerlas y las hagan. El problema es planteado en términos de producción de hábitos. Althusser afirmará que esta labor re-productiva de agentes de prácticas se halla administrada por la ideología, asegurada para las prácticas de explotación capitalistas por los AIE y llevada a cabo prácticamente el día de hoy por la II.

Pero hay que leer cuidadosamente. Este trabajo de desplazamiento conceptual es positivo: es la afirmación del carácter de producto de cualquier individualidad y la afirmación de las múltiples fuerzas productivas, mecanismos y operaciones que las producen.

\section{Re-des-conocimiento}

"Un juego de palabras" (Wortspiel) necesariamente impenetrable para quien lo profiere.

Louis Althusser

En la empresa de pensar los aparatos que producen y re-producen las relaciones de explotación actuales, Althusser alteró la concepción de la ideología que

${ }^{18}$ L. Althusser, "Ideología y aparatos ideológicos de Estado", en op. cit., p. 99. Negri ha señalado que en Althusser "de la acentuación de la crítica de las "relaciones de producción', la atención se ha desplazado a los procesos constitutivos de las nuevas 'fuerzas productivas'” (A. Negri, "Maquiavelo y Althusser", en op. cit., p. 19). 
dominaba el pensamiento marxista. Y "bajo el mismo nombre de ideología, introdujo un concepto fundamentalmente no marxista, presentándolo como el único concepto marxista posible de la ideología, el único compatible con el materialismo". ${ }^{19}$ La ideología se vuelve el aparato contemporáneo de producción y re-producción de efectos-sujeto necesarios para mantener el efecto-sociedad-capitalista. Pensar la relación ideología/poder contemporáneo es lo que se halla detrás de la reflexión sobre la II y los AIE. ${ }^{20}$

El dispositivo conceptual althusseriano ideología ya no funcionará de acuerdo a esa "fácil distinción entre el pensamiento y lo real fuera de él". ${ }^{21}$ Ahora, la "ideología existe siempre en un aparato y en su o sus prácticas. Esta existencia es material". ${ }^{22}$ La ideología deberá ser caracterizada como determinado conjunto de prácticas distintas a otras prácticas. Este conjunto de prácticas es ideológico porque trabaja de acuerdo a un mecanismo al que Althusser le da varios nombres: desconocimiento, reconocimiento, transposición, distorsión, imaginario. Así, el desconocimiento, la distorsión y la transposición se ejercen como prácticas sobre prácticas.

Étienne Balibar ha retraducido convenientemente el mecanismo ideológico: "La ideología no es la conciencia (tampoco la conciencia 'social' o 'colectiva', ni la 'falsa conciencia'): es, más bien, la inconsciencia". ${ }^{23}$ La ideología es una "estructura de desconocimiento" - en ciertos momentos se le nomina efecto-inconsciente. ${ }^{24}$ Este desconocimiento debe confundirse con un reconocimiento o "garantía". Por ello, afirma Althusser que la ideología funciona como

${ }^{19}$ É. Balibar, Escritos por Althusser, p. 86.

${ }^{20}$ Esta transformación en la manera de plantear la cuestión de la ideología se halla aceptada por los compañeros-contendientes de labor filosófica de Althusser. Rancière afirma: "Ideología es el nombre [...] del operador conceptual que organiza [...] el dispositivo político moderno" (Jacques Rancière, El desacuerdo. Política y filosofía. Trad. de Horacio Pons. Buenos Aires, Nueva Visión, 1996, p. 112); y Balibar: "El campo o 'elemento' de la política en general es la ideología", o "la ideología se encuentra en todas partes en la sociedad [...] el conflicto se encuentra en todas partes en la ideología" (É. Balibar, op. cit., pp. 84 y 96).

${ }^{21}$ Yann Moulier Boutang, "Le matérialisme comme politique aléatoire", en http:// multitudes.samizdat.net/Le-materialisme-comme-politique [consulta: 30 de marzo, 2010]. La traducción es mía.

${ }^{22}$ L. Althusser, "Ideología y aparatos ideológicos de Estado", en op. cit., pp. 123 y 127.

${ }^{23}$ É. Balibar, op. cit., p. 85.

${ }^{24}$ Althusser niega que la ideología y el inconsciente psicoanalítico se confundan: "no se puede hablar de 'sujeto del inconsciente" (L. Althusser, "Tres notas sobre la teoría de los discursos", en op. cit., p. 105). Sobre su proyecto de pensar la articulación del discurso inconsciente con el ideológico escribirá en 1977 en una carta para alguien que le preguntaba sobre tal relación inconsciente/ideología: "Lo único que puedo decirte con relativa certeza (puesto que mantengo relaciones muy lejanas con lo que pude escribir), es que me detuve 'en seco' (clara, claramente) ante la cuestión que te 
reconocimiento/desconocimiento, como "representación distorsionada". Y ésta como un mecanismo de ilusión/alusión. Así, para Althusser la ideología es un aparato práctico que produce sobre las prácticas de los individuos efectos de desconocimiento-reconocimiento-distorsión. ${ }^{25}$

Rancière ha descrito adecuadamente el mecanismo específico de este efecto ideológico como "distancia indefinidamente denunciada de las palabras y las cosas". ${ }^{26}$ Así, el mecanismo ideológico se ejerce como una diferencia entre decir y hacer, como una distorsión del hacer en el decir. Cuando el individuo sufre los efectos de una práctica ideológica "no ve lo que hace", ${ }^{27}$ y a cambio dice otra cosa que lo que hace, afirma “'un juego de palabras' (Wortspiel) necesariamente impenetrable para quien lo profiere" ${ }^{28} \mathrm{El}$ individuo que sufre el efecto ideológico utiliza un discurso que no es adecuado a sus prácticas, es decir, no dice lo que hace y no hace lo que dice hacer.

Althusser afirma que este mecanismo ideológico - que impide a los individuos "ver lo que hacen", "distorsionándoles" la "percepción" de lo que les acontece- es utilizado como el mecanismo central en la conformación de sujetos para la explotación; es decir, se halla institucionalizado como el capitalismo contemporáneo. Este distanciamiento es el efecto en el que se traduce el poder contemporáneo; pero, ¿cómo se produce ese distanciamiento entre las palabras y las cosas en el capitalismo contemporáneo? Sólo se comprende cabalmente este mecanismo cuando se le describe en los términos de una

interesa de las 'relaciones' entre la ideología (o las formaciones ideológicas concretas) y el inconsciente. Dije que debía existir ahí alguna relación, pero al mismo tiempo me impedí inventarla, considerando que, para mí, por el momento era un problema sin solución [...]. Y naturalmente me negué a proseguir, me negué a seguir a aquellos que, conocidos, intentaron llegar más lejos, como Reich u otros. El tema en el que fui más lejos debe ser en las notas finales del artículo sobre 'Freud y Lacan', mas ahí también, como en el artículo sobre los AIE, hay un límite no superado. Por ello, cuando me haces 'la pregunta': ‘¿cómo ves una elaboración conceptual entre inconsciente e ideología?', sólo puedo contestarte: no la veo. [...] Toda pregunta no implica forzosamente su respuesta" (ibid., p. 13).

${ }^{25}$ Antes que hacer uso de la teoría psicoanalítica del inconsciente para elaborar la teoría de la ideología, Althusser afirma: "fuimos spinozistas". Para Althusser, Spinoza elaboró la "primera teoría de la ideología con sus tres características: a) su 'realidad' imaginaria; b) su inversión interna, y c) su 'centro': ilusión del sujeto". Y con ello "fundó el sistema de este imaginario sobre la relación de los hombres con el mundo 'expresado' por el estado de sus cuerpos. Este materialismo de lo imaginario que abre el camino a [...] algo diferente de un 'conocimiento', el mundo material de los hombres tal como viven, el de su existencia concreta e histórica" (L. Althusser, Elementos de autocrítica, pp. 48-49).

${ }^{26} \mathrm{~J}$. Rancière, op. cit., p. 112.

${ }^{27}$ L. Althusser, "De El capital a la filosofía de Marx", en op. cit., p. 29.

${ }^{28}$ Ibid., p. 44. 
teoría de la "costumbre social" o del "hábito capitalista". Y es que el efecto ideológico, así como el "concepto ideológico de verdad", ${ }^{29}$ trabaja mediante un mecanismo de "recurrencia" ${ }^{30}$ Esta recurrencia es la repetición continua de determinadas prácticas. La recurrencia es el mecanismo del acostumbramiento, de la habituación. Las prácticas ideológicas son "prácticas normadas". Toda práctica normada es un hábito. A toda normalización capitalista de ciertas prácticas Althusser la llama AIE. Un aparato no es sino prácticas coaguladas de tan repetidas. De allí que Althusser afirme que la ideología sólo puede ejercerse mediante y como instituciones precisas y especializadas.

Para Althusser sólo hay aparatos ideológicos determinados, ciertas costumbres devenidas sociales, pasiones que se aceptan como cosas, ciertas relaciones sociales de producción repetidas y mantenidas. Todo aparato ideológico capitalista es el acostumbramiento de los hombres a la explotación. Es como si los AIE y su mecanismo ideológico insistieran en hacer sufrir a los individuos efectos de empirización. Una empirización de las costumbres que hiciera que los individuos tomaran sus pasiones por las cosas mismas, sus palabras por sus actos, sus cosquillas por el mundo. Que les provocará la "ilusión" de que las prácticas capitalistas son las únicas existentes, la sensación de que el capitalismo es su vida misma. Althusser afirma que los individuos que sufren los efectos ideológicos desconocen sus prácticas vitales, que sólo re-conocen lo que les pasa, que toman por "evidencia" lo que viven, que sólo pueden garantizar lo que hacen cotidianamente. Esto es un efecto-sociedad. Los AIE capitalistas son máquinas que aseguran la no puesta en discusión de las costumbres sociales de explotación. Es como si Althusser pensara que las relaciones de producción capitalistas contemporáneas trabajaran manteniendo estúpidos a los hombres. Como si el capital fuera, para funcionar, un mecanismo de mantenimiento de una condición de estupidez. El estúpido es aquel que no puede ver que lo que hace le hace sufrir, y lo sigue haciendo, es aquel que supone que lo que piensa es lo que hay. Y es cierta manera capitalista de usar y producir la costumbre la que vuelve estúpido al individuo. Es la estructura de costumbre recurrente de las prácticas capitalistas la que genera este distanciamiento entre la descripción y la explicación de lo que se hace.

De este modo se logra en el capitalismo la "producción de la sumisión" 31 y la "reproducción de la capacidad de los agentes de la explotación". ${ }^{32}$ Se puede decir que los AIE "están al cuidado" de que los actos materiales de los indivi-

${ }^{29}$ L. Althusser, "Tres notas sobre la teoría de los discursos", en op. cit., p. 142.

${ }^{30}$ L. Althusser, Elementos de autocrítica, p. 32. A esta "especificidad recurrente" es a lo que Althusser llama "eternidad" de la ideología.

${ }^{31}$ L. Althusser, "Ideología y aparatos ideológicos de Estado", en op. cit., p. 101.

${ }^{32}$ Ibid., p. 103. 
duos se inserten en prácticas normadas por rituales materiales definidos por el aparato ideológico material. Pero el verdadero problema es que este cuidado se ejerce sobre los individuos por los propios individuos. La "sutil dominación cotidiana" 33 es en última instancia un trabajo sobre sí. Los AIE capitalistas son "mecanismos que producen un resultado vital". ${ }^{34}$ Este resultado vital, estas pasiones que se mantienen, es la vida explotada de los individuos, un sujeto.

\section{Evidentia}

La estructura de un discurso no es la de una práctica. [...] un discurso no produce más que efectos, [...] las prácticas originan modificaciones-transformaciones [...]. Esto no quiere decir que los discursos no ejerzan eficacia sobre objetos reales, pero si lo hacen es sólo por su inserción-articulación en dichas prácticas, que los utilizan entonces como instrumentos en su "proceso de trabajo".

Louis Althusser

El efecto ideológico es la producción de hábitos sociales, la generación del acostumbramiento a un determinado conjunto de prácticas llamadas sujeto -en el capitalismo contemporáneo la producción de instituciones que producen y mantienen relaciones de explotación y de los individuos que quieren adecuarse a ellas. La ideología es una "tecnología de la explotación".35 Y sobre este mecanismo tecnológico que genera este efecto, Althusser afirma: "La existencia de la ideología y la interpelación de los individuos en tanto sujetos es una y la misma cosa". ${ }^{36}$

Althusser en diferentes textos nos da varias caracterizaciones del funcionamiento de la II: "La ideología interpela a los individuos en cuanto sujetos"; 37 o: "Todo individuo humano, es decir social, sólo puede ser agente de una práctica social si reviste la forma de sujeto". ${ }^{38}$ Mas esta forma de caracterizar la II causa problemas al concebir su operación como lenguaje y su efecto sobre un cuerpo individual. Por ello se arriesga una lectura del efecto productor de

33 Ibid., p. 107.

${ }^{34}$ Ibid., p. 119.

${ }^{35}$ L. Althusser, "Nota. Sobre la crítica del culto a la personalidad", en op. cit., p. 95.

${ }^{36}$ L. Althusser, "Tres notas sobre la teoría de los discursos", en op. cit., p. 133.

${ }^{37}$ Ibid., p. 130.

${ }^{38}$ L. Althusser, "Observación sobre una categoría: 'proceso sin sujeto ni fin(es)', en Para una crítica de la práctica teórica, p. 76. 
desconocimiento de la ideología en términos retóricos: como la "ilusión de la todopotencia de la palabra que prescribe a la cosa ser al nombrarla". ${ }^{39}$

Althusser es enfático: "la ideología no es un mandamiento [...]; no es una violencia cruda $[\ldots]$, no es una exhortación pura y simple, sino una empresa de convicción-persuasión". ${ }^{40}$ La ideología es una empresa retórica, su efecto es persuasivo y la II es una figura retórica compleja. Toda la labor que Althusser emprendió para echar a funcionar una "teoría general del discurso" que analizara las "leyes de combinación, sustitución, elisión, subrepción, amontonamiento, etcétera", los mecanismos de "sustracción y subversión" del lenguaje, tiene como pregunta principal: “¿en qué nivel operan con respecto a las leyes de la metonimia y de la metáfora? Los tropos, las figuras de estilo, ¿dónde hay que colocarlos?" 41 Althusser lo dice en voz alta: "en filosofía sólo con metáforas se puede pensar". ${ }^{42}$ Así, Althusser elaborará sus conceptos a partir de figuras del lenguaje, comenzará a pensar de acuerdo a los mecanismos del lenguaje figurado.

Si del significado etimológico de la palabra, Althusser utilizará, al menos, dos sentidos -interrupción y perturbación-, trabajará la interpelación como una máquina retórica compleja. Se hallan ensambladas para su funcionamiento varias figuras retóricas que operan al unísono: hipotiposis (atestiguar la viva descripción de un personaje), apóstrofe (interrumpir el discurso para incrementar el énfasis con que se enuncia), deprecación (interrumpir el discurso para mover al ánimo de los oyentes a favor propio), digresión (interrupción del hilo temático del discurso antes que se haya completado una de sus partes para darle un desarrollo inesperado), dubitación (el orador se finge vacilante y perplejo para solicitar ayuda sobre cómo proseguir el discurso), prosopopeya (atribuir a las cosas cualidades que no corresponden con su género vital). Pero es una figura en la que encontrará el mecanismo de la II: la evidencia. La evidentia es una de las variantes de la descripción, ella tiene por objetivo presentar todo lo que conforma los personajes de un relato. La evidencia "contiene un cúmulo de pormenores precisos, intensamente claros y verosímiles, de modo que resulta viva y enérgica, y permite al receptor compenetrarse como testigo presencial". ${ }^{43}$ Es decir, la evidencia produce, sobre quien la lee o escucha, un "impacto sobre la afectividad", induciéndole, como afirma Barthes, una "escena que uno se representa vivamente": la escena de sí mismo como persona. Althusser la utiliza porque esta figura retórica "pone en evidencia" el efecto

${ }^{39}$ Y. Moulier Boutang, "Le matérialisme comme politique aléatoire", en op. cit.

${ }^{40}$ L. Althusser, "Tres notas sobre la teoría del discurso", en op. cit., p. 118.

${ }^{41}$ Ibid., p. 144.

${ }^{42}$ L. Althusser, Elementos de autocrítica, p. 14, n. 1.

${ }^{43}$ Helena Beristáin, Diccionario de retórica y poética. México, Porrúa, 1992, p. 138. 
que el lenguaje ejerce sobre los individuos: persuade. La persuasión o convencimiento induce-produce las verdades sobre las que los individuos pensarán, dirán y vivirán sus prácticas. Es de acuerdo a este énfasis que Althusser hará del poder persuasivo del lenguaje -lo que llama, en otra parte, la "presencia eficaz" del "eficaz absoluto"- el mecanismo de la II. La II se trata así de "una clase muy especial de evidencia”.

Lo que más le importa a Althusser en el mecanismo retórico de la evidencia es que muestra perfectamente que la II no sería eficaz sin el deseo de respuesta de los individuos. La II por sí sola no constituye a los sujetos, son los individuos al "responder: 'sí, soy yo" los que se constituyen como sujetos en sí mismos. El mecanismo de evidencia de la II es ineficaz si el individuo no responde a la interrupción que lo perturba y asume el personaje que se le propone. La constitución de sujetos es respuesta de individuos. La interpelación debe concebirse como una máquina de constitución de respuestas por adelantado a preguntas no hechas. La constitución de sujetos en las relaciones de explotación actuales funciona como una única respuesta a lo que acontece: como si los individuos no pudieran responder de otra manera a las circunstancias históricas, sino conformándose a sí mismos en agentes de explotación. Lo que "cuidan" los AIE es que esta respuesta sea la única posible y que se haga hábito. Es sobre esta potencia de respuesta que Althusser pondrá en funcionamiento la emergencia de una práctica revolucionaria. Pues la revolución es, para Althusser, una respuesta a las circunstancias históricas.

Althusser halló las fórmulas provisionales “así sea” o “isí, está bien, es así!” para describir el efecto de habituación de la ideología. Por ello, a veces Althusser llama "garantía", otras "alusión" y otras "presuposición" a este efecto de evidencia de sí mismo. Así escribe:

Como todas las evidencias, incluso las que hacen que una palabra "designe una cosa" o "posea una significación" (por tanto, incluso las evidencias de la "transparencia del lenguaje"), ésta -que usted y yo somos sujetos y que eso no es ningún problema- es [...] el efecto ideológico elemental. Lo propio de la ideología, en efecto, es el imponer (sin que se advierta, se trata de "evidencias") las evidencias como evidencias, que sólo podemos reconocer y ante las cuales sólo nos queda la natural e inevitable reacción de exclamar (en voz alta o en el "silencio de la conciencia”): ¡Evidente! ¡Exacto! ¡Verdad!

En esta reacción se ejerce la función de reconocimiento ideológico que es una de las dos funciones de la ideología como tal (su envés es la de desconocimiento). ${ }^{44}$

${ }^{44}$ L. Althusser, "Ideología y aparatos ideológicos de Estado", en op. cit., p. 131. 
La II es "la producción de lo que nos parece la evidencia misma":45 la experiencia vivida de nosotros mismos. De este modo la ideología se traduce en "lo tenaz de las evidencias" de nosotros mismos como sujetos a las relaciones de explotación. Y es que la ideología es un mecanismo que instaura en los individuos el empirismo tanto como pensamiento como forma de sensibilidad. Un empirismo que obliga a responder de una única manera a las condiciones históricas de explotación: sujetándose a sí mismo. Así, Althusser escribe "el empirismo es el enemigo filosófico número uno de la lucha de clases del proletariado". ${ }^{46}$ Contra este empirismo de las pasiones del sí mismo, Althusser tratará de implementar diferentes prácticas que "atenten contra las 'evidencias' del sentido común". ${ }^{47}$ Esta implementación de prácticas diferentes a las ideológicas es todo el cometido de la elaboración de una "ciencia revolucionaria". ${ }^{48}$

\section{Producción aleatoria}

Sólo poco a poco se emancipan entre nosotros los cuerpos.

Friedrich Nietzsche

Es cierto que "no se piensa en la filosofía sino bajo metáforas. Pero bajo estas metáforas se encuentran problemas teóricos [políticos] que nada tienen de metafórico". ${ }^{49}$ El problema más apremiante es el de la revolución, o prácticas que alteren, modifiquen y acaben con las relaciones de explotación. De hecho, Althusser afirma: "Que desaparezca el problema de 'el hombre sujeto de la historia' no quiere decir que desaparezca el problema de la acción política. ¡Completamente al contrario! La crítica del fetichismo burgués de 'el hom-

${ }^{45}$ L. Althusser, "De El capital a la filosofía de Marx", en op. cit., p. 51.

${ }^{46}$ É. Balibar, "Algunas cuestiones de la crisis de la teoría marxista y del movimiento comunista internacional" apud "Anexo. Nota biográfica", en op. cit, p. 106.

${ }^{47}$ L. Althusser, "Observación sobre una categoría: 'proceso sin sujeto ni fin(es)", en op. cit., p. 76.

${ }^{48}$ Lo que distinguiría el discurso ideológico del científico es el funcionamiento de las palabras. La palabra en el discurso ideológico es descriptiva pero no explicativa. El discurso ideológico produce un efecto que no permite pensar sus condiciones y mecanismos. Es decir, en la ideología la metáfora no puede pensarse a sí misma. En cambio en el lenguaje más científico se logra pensar estos mecanismos. La pretensión del discurso científico es pensar lo que se entrega en una descripción. Así, la ciencia revolucionaria puede caracterizarse como el lenguaje que analiza los mecanismos retórico-ideológicos. Este lenguaje está conformado por conceptos que funcionan a la vez como descripción de palabras metafóricos y como producción de otros discursos.

${ }^{49}$ L. Althusser, Elementos de autocrítica, p. 54. 
bre' le da toda su fuerza". ${ }^{50}$ Retraduzcamos de acuerdo al efecto positivo de las afirmaciones: la puesta en funcionamiento de la tesis de la producción de individualidades en los aparatos y mecanismos de la II permiten pensar otros aparatos y otros mecanismos lingüísticos y prácticos que no funcionen para producir el efecto-evidencia subjetividad. O mejor, sólo mediante la implementación del aparato capitalista de producción de efectos-sujeto y su mecanismo interpelativo es que es dable pensar y practicar otros aparatos y otros mecanismos de producción de individuaciones que no pasen por la función sujeto.

Althusser defiende que el mecanismo de la ideología "concierne al individuo", y asegura que su cometido es "asegurar [la explotación] 'por la palabra'" ${ }^{51}$ El resultado de tal enunciación conceptual es que todo individuo será agente de prácticas sociales en la sociedad históricamente determinada por las relaciones de explotación capitalista, si y sólo si deviene sujeto. Pero este resultado es problemático, ya que produce contingentemente una distinción individuo/sujeto. El problema de la enunciación es decidir si afirma que la única forma de individuos será la de sujeto, consentir o no las prácticas subjetivas como las únicas dables. A esta distinción Althusser la llama metafórica.

Althusser escribe varias fórmulas que puede permite elaborar la problemática. La primera afirma que "los individuos siempre han sido sujetos. Los individuos, por tanto, son 'abstractos' respecto a los sujetos, que siempre ha habido". ${ }^{52}$ Tal enunciación confirma la identidad práctica, y queda sin sentido la afirmación de la "abstracción" de los individuos. Pero en el mismo texto más adelante escribe matizando: "Por más que sepamos que el individuo es siempre sujeto, continuamos empleando este término que resulta cómodo por el efecto de contraste que produce". ${ }^{53}$ Aquí Althusser afirma un "siempre" de la identidad práctica, pero matiza con una figura retórica: el contraste o antítesis. La antítesis es un tropo que contrapone una idea a otra. Esta contraposición no llega a ser una contradicción, como en el caso del oxímoron y de la paradoja, lo que implica que la contraposición señala la repetición de una idea común que comparten los términos. Además, la antítesis aclara y presenta con más viveza los sentidos de los términos. Finalmente, los términos pueden coordinarse o subordinarse. Así, si individuo se contrapone a sujeto, entonces debe haber algo común y deben diferenciarse.

Este procedimiento de contraste permite afirmar conceptualmente que lo común entre el individuo y el sujeto es su producción y su funcionamiento

${ }^{50}$ L. Althusser, "Respuesta a John Lewis", en op. cit., p. 38.

${ }^{51}$ L. Althusser, "Ideología y aparatos ideológicos de Estado", en op. cit., p. 102.

52 Ibid., p. 133.

${ }^{53}$ Ibid., p. 145, n. 18. Las cursivas son mías. 
práctico, y su diferencia se halla en el modo de funcionar, en la especificidad de sus prácticas. Habría, pues, un criterio de distinción, o de contraste, o de escisión de prácticas. Es en este sentido que Althusser afirma: "Para el discurso ideológico hay únicamente sujetos ideológicos"; ${ }^{54}$ es decir, sólo hay sujetos ideológicos. Y por ello agregaría que "la ideología no tiene fuera (respecto a sí misma), pero, al mismo tiempo, que la ideología sólo es fuera (respecto a la ciencia y a la realidad)" ${ }^{55}$ Esto es, fuera de los sujetos hay formas de individuación asubjetiva; o en otras palabras, la ideología se ejerce en prácticas que no son las de la ciencia y las de la realidad. Así, si todo sujeto se halla reducido a ciertas prácticas que lo conforman, prácticas interpelativas determinadas por las condiciones de explotación de una sociedad determinada y las circunstancias históricas capitalistas, entonces un individuo debe poder ser el ejercicio de prácticas diferentes a las de la II. Un individuo se acaba en el ejercicio de otras prácticas fuera de las de actuar como agente de relaciones sociales capitalistas. Todo se juega para Althusser en las prácticas. Siempre hay formas de actuar de otra manera, por muy reducido que sea su ejercicio. La palabra "individuo" señala, para Althusser, esa multiplicidad de prácticas no reducidas a la figura de sujeto capitalista. ${ }^{56}$

Es así que el contraste individuo/sujeto debe pensarse de acuerdo a la distinción de las prácticas ideología/revolución. Los AIE se hallan conformados por prácticas normadas que repiten y mantienen las relaciones de explotación, la práctica revolucionaria debe pensarse, al menos, como práctica no normada de acuerdo a los criterios de explotación. Balibar escribe: "una 'práctica' en el sentido fuerte del término [es decir, revolucionaria] -sea política, estética, científica- produce efectos reales en la medida en que cambia la posición relativa de los 'sujetos'". ${ }^{57}$ Una práctica revolucionaria produce otros mecanismos de funcionamiento de los individuos. Una práctica revolucionaria es una máquina de producción de individualidades contrapuestas a las de la II. Así, los individuos son un producto, "los hombres reales son pues el punto de llegada". 58

${ }^{54}$ L. Althusser, "Tres notas sobre la teoría de los discursos", en op. cit., p. 121.

55 Ibid., p. 133.

${ }^{56}$ Moulier Boutang afirma que esta apertura hacia nuevas maneras de individuación se halla en el centro de la preocupación althusseriana: "Althusser desconfiaba de toda forma de construcción que reposara sobre la noción de persona. Este término era para él una noción teológica, y no un concepto o una categoría filosófica [...]. No le gustaba tampoco el término 'sujeto', en el que veía o bien una inyunción, el producto de un sujetamiento [...], o bien una filosofía idealista, o, finalmente, un enigma sin fondo que el psicoanálisis se arriesgaba circunvalar [...]. Al contrario, el individuo [...] le parecía una categoría maniobrable en 'la lucha de clases en la teoría" (Y. Moulier Boutang, "Le matérialisme comme politique aléatoire", en op. cit.)

${ }^{57}$ É. Balibar, op. cit., p. 89.

${ }^{58}$ L. Althusser, "Respuesta a John Lewis", en op. cit., p. 37. 
Althusser señala la labor positiva de su empresa: para los "hombres reales [...] precisamente para verlos tal cual son y para liberarlos de la explotación de clase, se realiza esta revolución [...], son algo completamente distinto de ejemplares, multiplicados a voluntad, de la imagen burguesa originaria" ${ }^{59}$ Pero qué son estos "individuos concretos" completamente distintos al sujeto. Althusser escribe en una carta del 13 de septiembre, dirigida a su amiga Franca: "Lo que existe, en el sentido amplio de existir; son estos objetos reales que ahora llamo, tomando un concepto de Spinoza, 'esencias singulares'" ${ }^{60}$ Un individuo no es una autoconciencia, tampoco una libertad irrestricta, mucho menos una falta. Un individuo halla su forma de expresión en el cuerpo y en lo que Althusser llamó "materialismo aleatorio". Sólo esta reformulación de un materialismo contingente abriría las potencias de prácticas revolucionarias y de vidas no explotadas. Althusser afirma: "lo culminante del materialismo es el materialismo aleatorio, requerido para pensar la apertura del mundo hacia el acontecimiento, la imaginación inaudita y también hacia toda práctica viva, incluyendo la política". ${ }^{61}$

El materialismo aleatorio es una "teoría del cuerpo". Pero del cuerpo entendido como encuentro contingente de elementos singulares: fuerzas, individuos, piedras, animales, etcétera. Así, Althusser escribe que "Para que un ser sea (un cuerpo, un animal, un hombre, un Estado o un príncipe) es necesario que un encuentro haya tenido lugar". ${ }^{62}$ Un cuerpo se reduce al "concurso de la condiciones materiales que lo imponen", ${ }^{63}$ a un "concurso imprevisible, increíblemente complejo y paradójico pero necesario en su contingencia”. ${ }^{64}$ El carácter de azaroso exige pensar que:

Nunca un encuentro llevado a cabo y que no sea breve sino duradero podrá garantizar que mañana aún durará, en vez de deshacerse. Igual que habría podido no tener lugar, puede no seguir teniendo lugar [...]. La historia no es más que la revocación permanente del hecho consumado [...], sin que se sepa, ni de antemano ni nunca, dónde ni cómo se producirá el acontecimiento de su revocación. Simplemente llegará un día. ${ }^{65}$

${ }^{59}$ Ibid., pp. 36-37. Las cursivas son mías.

${ }^{60}$ L. Althusser, Escritos sobre psicoanálisis. Freud y Lacan, p. 102.

61 "Algunas reflexiones del último Althusser", entrevista de 1984 hecha por Fernanda Navarro en Utopías, núm. 8, febrero-marzo, 1991, p. 13.

${ }^{62}$ L. Althusser, Para un materialismo aleatorio, p. 59.

${ }^{63}$ L. Althusser, Elementos de autocrítica, p. 66.

${ }^{64}$ Ibid., p. 20.

${ }^{65}$ L. Althusser, Para un materialismo aleatorio, p. 39. 
La contingencia se vuelve la revocación continua de toda evidencia, o mejor, su reformulación azarosa continuada. La contingencia debe ser entendida como la "eficacia de la causa ausente" ${ }^{66}$ Lo que determina, en última instancia, toda práctica es siempre el azar.

Así, el individuo debe ser pensado y practicado, de acuerdo a esta teoría del cuerpo aleatorio, como una constelación diferencial de prácticas contingentes. Una constelación aleatoria cuya operación es multiplicar los aparatos y los mecanismos productores de hábitos aleatorios.

${ }^{66}$ L. Althusser, Elementos de autocrítica, p. 37. Es sólo a partir del término contingencia que se comprenderá adecuadamente el concepto de sobredeterminación o determinación en última instancia. 